\title{
Determinants of Residency Program Choice in Two Central African Countries: An Internet Survey of Senior Medical Students
}

Ulrick S. Kanmounye, ${ }^{1}$ Mazou Temgoua, ${ }^{2}$ Francky T. Endomba. ${ }^{3}$

\begin{abstract}
Background: Central African countries have an increasing burden of disease, low specialist workforce densities, and under-resourced postgraduate medical education. The residency program choice of today's medical students will determine specialist workforce density in the near future. This study aims to elucidate the factors that influence the choice of residency programs among medical students of two Central African countries. Methods: We designed an online questionnaire in French and English with closed-ended, open-ended, and Likert scale questions. Links to both forms were shared via the international messaging application, WhatsApp, and data were collected anonymously for one month. Respondents were sixth- and seventh-year medical students enrolled in nine Cameroonian and Congolese schools. The threshold of significance was set at 0.05 for bivariate analysis. Results: There were 149 respondents in our study, $51.7 \%$ were female, and $79.2 \%$ were from Cameroon. Almost every student ( $98 \%)$ expressed the wish to specialize, and a majority (77.2\%) reported an interest in a residency program abroad. Preferred destinations were France ( $13.7 \%)$, Canada ( $13.2 \%)$, and the U.S.A. (11.9\%). The most popular specialties were cardiology $(9.4 \%)$, pediatrics $(9.4 \%)$ and obstetrics and gynecology $(8.7 \%)$. The choice of specialty was made based on the respondent's perceived skills $(85.9 \%)$, anticipated pay after residency $(79.2 \%)$, and patient contact $(79.2 \%)$. Conclusion: Understanding which specialties interest Cameroonian and Congolese medical students and the reasons for these choices can help develop better local programs.
\end{abstract}

Key Words: Career choice; Internship and residency; Surveys and questionnaires; Cameroon; Democratic Republic of the Congo (Source: MeSH-NLM).

\begin{abstract}
Introduction
Cameroon and Democratic Republic of Congo (DRC) are Central African countries with high burdens of infectious and maternal diseases, low health investments, and high incidences of catastrophic health expenditure due to a lack of universal health coverage., ${ }^{1,2}$ The overburdened Cameroonian and Congolese health systems are stressed further by conflicts and disasters.3,4 Limited medical school admissions and local residency positions are pushing medical graduates to educational migration. Also, a considerable percentage of African medical graduates tend to go abroad because foreign programs are perceived to be of higher quality.5,6 This decreases the physician workforce density and limits patient access to specialist care in African countries. Specialist care plays a significant role in the healthcare system as it leads to prompt diagnosis, adapted care, and generally better outcomes for patients.7,8 Postgraduate medical education (PGME) programs should equip their graduates with the skills to tackle the nation's public health challenges. Understanding the determinants of residency program choice can equally help bridge the disparities in certain specialties. For example, women are poorly represented in some specialties 9,10 despite making up more than half of the medical student body. ${ }^{11,12}$ This disparity is accentuated in African society, where women tend to be less interested in specialties that are viewed as "demanding." 13,14
\end{abstract}

Cameroon has 1,420 general practitioners and 422 specialists serving 25 million inhabitants. ${ }^{15}$ Admission into the 7-year medical school programs is through a unique national examination for undergraduates, and successful candidates get into one of 8 medical schools (six public and two private). The first three years are pre-clinical, the next three are clinical, and the last year is reserved for the thesis. At the end of the sixth year, students take a national examination (Examen National de Synthèse Clinique et Thérapeutique) made of a written and a practical section. Successful candidates can apply for an academic specialty program known as internat, and if selected, they then go on to start their specialty the following year. Those who are not interested in internat and those who failed to get into internat can apply for another specialty program known as résidanat once they have totaled at least two years of general practice.

The DRC, on the contrary, has 84 million inhabitants and 4,500 (2,000 specialists and 2,500 general practitioners) of the country's 25,000 physicians that practice in the capital city. The number of medical schools has grown exponentially.16 From 19 nationwide in 2010, there are now 25 in the capital city (Kinshasa) alone. ${ }^{17}$ Training in the DRC is divided into three pre-clinical years called graduat and four clinical years called doctorat. The last year of doctorat, quatrième doctorat, is spent doing rotations for a period between 14 to 18 months divided into at least: 1-month neurology, 1-month psychiatry, 4-month medicine, 4-month surgery, 4-month obstetrics and gynecology, and 4month pediatrics rotations. Medical graduates can apply for residency if they pass the admissions tests organized by each program.

Cameroonian and Congolese medical graduates are considered fit to practice as soon as they get licensure from their respective national medical bodies. The state is the major employer in both countries and the state's budget limits recruitment. ${ }^{18}$ There are no rural practice

\footnotetext{
MD, Department of Neurosurgery, Faculty of Medicine, Université Technologique Bel Campus, DR Congo

2 Department of Public Health, Success Pro Research Academy, Yaounde, Cameroon ; Department of Cardiology, Faculty of Medicine and Biomedical Sciences, Yaounde, Cameroon 3 Health Economics \& Policy Research and Evaluation for Development Results Group (HEREG), Yaounde, Cameroon; Psychiatry Internship Program, Centre Hospitalier Universitaire, Dijon, France
}

About the Author: Ulrick Sidney is a medical graduate and a research associate at the Program in Global Surgery and Social Change, Harvard Medical School. He is equally the President of the Association of Future African Neurosurgeons.

Correspondence:

Ulrick Sidney Kanmounye

Address: 17, 8ème Rue Limete / Quartier Industriel, Congo - Kinshasa

Email: ulrick kanmounyekouokam@hms.harvard.edu

Med Students • 2020 | Jan-Apr | Vol 8 | Issue 1 
requirements for recent medical graduates, and most physicians recruited by the state are assigned to rural health centers unless they are admitted into a PGME program, in which case, they will be assigned to a teaching hospital. Little is known about how Cameroonian or Congolese medical students choose their residency programs. We aimed to identify the determinants of residency program choice among senior year medical students in Cameroon and the DRC.

\section{Materials and Methods}

Study Design and Participants

We conducted a descriptive cross-sectional study, and our target population was defined as sixth- and seventh-year students enrolled in Cameroonian and Congolese medical schools. We distributed our survey to students of 9 medical schools: 6 Cameroonian and 3 Congolese. Two of the eight Cameroonian medical schools, the University of Dschang and the University of Ngaoundere, were created less than three years ago and had no senior medical students at the time of our study. We recruited students from the Faculty of Medicine and Biomedical Sciences, Yaounde; Higher Institute of Medical Technologies, Yaounde; Faculty of Medicine and Pharmaceutical Sciences, Douala; Faculty of Health Sciences, Buea; Faculty of Health Sciences, Bamenda and Higher Institute of Health Sciences, Bangangte. Cameroon has two official languages, French and English. English is the primary teaching language in the Faculty of Health Sciences, University of Bamenda, and the Faculty of Health Sciences, University of Buea, while French is the primary teaching language in the other medical schools. In the DRC, we recruited from Bel Campus Technological University, Kinshasa; Faculty of Medicine, Kinshasa; and Faculty of Medicine, Kamina. All Congolese medical schools use French as their official language. The study population sampling was consecutive and convenient, and participant consent was sought before beginning the survey.

\section{Questionnaire}

The questionnaires were self-administered in both French and English. Links to the online Google Forms (Google LLC, CA, U.S.A.) questionnaires were shared via the official class WhatsApp (WhatsApp Inc, CA, U.S.A.) groups and via text messages. A restriction on the number of survey responses from a single device limited duplicate responses, and all respondents were given information on the aims and risks of the study.

The questionnaire comprised five sections: the first section included sociodemographic data (gender, age, marital status, medical school, medical schools' private/public status, year of study). The second section covered the students' preferred residency programs and the reasons for choosing these programs. The questionnaire evaluated the importance of 11 factors using 5-point likert scale questions. These factors had previously been identified during a formal group discussion between the authors and a sample of 21 Cameroonian and Congolese senior medical students. This same group was used to pilot the online survey, and their responses were not included in the final analysis. The following section covered the intention to migrate, destination, and reasons for migrating or not migrating. The fourth section explored whether the students had been encouraged or discouraged by someone close to them. Finally, the last section covered whether the medical students had previously changed their minds. Data were collected anonymously, and ethical clearances were obtained from Institutional Review Boards in Cameroon and the DRC.

\section{Specialty classification}

We classified specialties into medical specialties (acute internal medicine, allergy, cardiology, clinical genetics, dermatology, endocrinology, gastroenterology, general internal medicine, geriatric medicine, immunology, infectious diseases, medical oncology, ophthalmology, neurology, palliative medicine, nephrology, nuclear medicine, pneumology, rheumatology, and sports medicine), surgical specialties (cardiothoracic surgery, general surgery, neurosurgery, oral and maxillofacial surgery, trauma and orthopedic surgery, otolaryngology, pediatric surgery, plastic surgery, urology surgery, and vascular surgery) and other specialties. Data analysis
Data was exported from Google Forms to Excel (Microsoft Corp, WA, U.S.A.), coded and analyzed using SPSS V24 (Statistical Package for the Social Sciences, SPSS Inc, U.S.A.). $95 \%$ confidence intervals, bivariate, and multinomial regression analyses were run. The alpha value was set at 0.05 . The Likert responses were organized into three categories: strongly disagree and disagree, undecided, and agree and strongly agree. Agree and strongly agree were the reference for the level of importance of each determinant, while surgical specialties were the reference category for PGMEs. The visualizations were generated using Tableau Public V2019.4.1 (Mountain View, CA, U.S.A.).

\section{Results}

of the 186 eligible final year medical students approached in Cameroon and the DRC, 149 respondents (response rate: $80.11 \%$ ) consented to the study, and the same number completed the survey. There were no incomplete surveys, and we were unable to distinguish abandonments from non-response. Following data cleaning and analysis, we did not find ineligible respondents among our sample. The mean age was 25.29 years $\pm 1.97,52 \%$ of participants were female, $86.6 \%$ were single, $79.2 \%$ went to school in Cameroon, $56.4 \%$ were in public schools, and $75.8 \%$ were in their seventh year of medical school. Almost every participant (98\%) expressed a firm desire to get into residency, 115 respondents (77.2\%) intended to do their residency abroad, and 114 (76.5\%) reported that they would come back home after their training abroad. Those who wished to return after their residency training stated the need to help the vulnerable $(40.3 \%)$ and the need to serve the state (36.9\%). Some answers from our respondents are below:

"We lack doctors in my preferred specialty in my country, and I wish to improve the health of my countrymen."

"My country needs me more, plus we were trained to take care of the sick and needy. Patients exist everywhere, so [physicians] should equally exist everywhere."

Most participants (58.4\%; $95 \% \mathrm{Cl}: 50 \%-66.4 \%$ ) had previously changed their minds on their specialty choice. 133 (89.3\% 95\% Cl: 83.1\%-93.7\%) respondents reported that they had been advised to take up a specialty. These students had been encouraged by a family member $(64.4 \%, n=133)$, a friend $(30.2 \%, n=133)$, or a teacher $(21.5 \%, n=133)$ to choose a specialty over another. The most commonly recommended specialties were obstetrics and gynecology $(18.8 \%, n=133)$ and pediatrics $(12.8 \%, n=133)$. Sixty-four students $(43.0 \%, n=149)$ followed the advice given to them (Table 1).

When asked what they would choose between their least favorite specialty abroad and their favorite specialty at home, $104(69.8 \% ; 95 \%$ Cl: $61.7 \%-77 \%)$ chose their favorite specialty. $77(51.7 \%)$ students agreed they would accept a residency offer if it entailed having to practice in a rural area at the end of residency while $46(30.9 \%)$ were hesitant. Students that hesitated or refused to accept such an offer reported they might change their minds if rural outposts were better equipped $(10.7 \%)$ or if they were guaranteed career advancement $(5.4 \%)$ or if they were given financial incentives $(4.0 \%)$.

Participants from this study chose Africa $(30.2 \%)$ as the second most popular continent for residency program choice behind Europe (38.2\%). The most popular countries for residency training were France $(13.7 \%)$, Canada $(13.2 \%)$, and the U.S.A. (11.9\%) (Figure 1). The main reason for wanting to train abroad was to get better training $(68.5 \%)$. Additionally, $6.7 \%$ of students wished to train abroad because they felt foreign programs were more prestigious, while $3.4 \%$ wished to train abroad because their preferred specialty was not available for PGME in their home country. Some interesting quotes by our respondents:

"I wish to train abroad because education and remuneration are better than at home. There are more opportunities to grow abroad, and I can directly access my specialty without having to wait to gain experience." 
"The specialty I wish to do is not available in my country, and I wish to explore another country."

Only seven students decided to train in their country. They cited family (2.7\%) and patriotism $(2.0 \%)$ as reasons for training in their homeland. The destination for residency training was chosen based on the reputation of the country's training programs $(45.0 \%)$, the host country's language (9.4\%), and opportunities ( $7.4 \%)$.

Table 1. Cameroonian and Congolese Medical Students' Sociodemographic Characteristics, Intention to Specialize and Intention to Migrate in Online Survey by Frequency and Percentage.

\begin{tabular}{|c|c|c|c|}
\hline Characteristic & $\begin{array}{l}\text { All (\%) } \\
{[n=149]}\end{array}$ & $\begin{array}{c}\text { Cameroon (\%) } \\
{[n=115]}\end{array}$ & $\begin{array}{c}\text { The DRC (\%) } \\
{[n=34]}\end{array}$ \\
\hline Mean Age & 25.29 & 24.91 & 26.56 \\
\hline \multicolumn{4}{|l|}{ Gender } \\
\hline Female & $77(51.7)$ & $66(44.3)$ & $11(7.4)$ \\
\hline Male & $72(48.3)$ & $49(32.9)$ & $23(15.4)$ \\
\hline \multicolumn{4}{|l|}{ Relationship status } \\
\hline Single & $129(86.6)$ & $100(67.1)$ & $29(19.4)$ \\
\hline Engaged/Married & $20(13.4)$ & $15(10.1)$ & $5(3.4)$ \\
\hline \multicolumn{4}{|l|}{ School year } \\
\hline Seventh & $113(75.8)$ & $84(56.4)$ & $29(19.4)$ \\
\hline Sixth & $36(24.2)$ & $31(20.8)$ & $5(3.4)$ \\
\hline \multicolumn{4}{|l|}{ Medical school } \\
\hline Public & $84(56.4)$ & $71(47.7)$ & $13(8.7)$ \\
\hline Private & $65(43.6)$ & $44(29.5)$ & $21(14.1)$ \\
\hline \multicolumn{4}{|l|}{$\begin{array}{l}\text { Intent to get into } \\
\text { residency }\end{array}$} \\
\hline Yes & $146(97.8)$ & $113(75.8)$ & $33(22.1)$ \\
\hline Maybe & $3(2.0)$ & $2(1.3)$ & $1(0.7)$ \\
\hline \multicolumn{4}{|l|}{$\begin{array}{l}\text { Intent to migrate } \\
\text { for residency } \\
\text { training }\end{array}$} \\
\hline Yes & $115(77.2)$ & $84(56.4)$ & $31(20.8)$ \\
\hline Maybe & $27(18.1)$ & $24(16.1)$ & $3(2.0)$ \\
\hline No & $7(4.5)$ & $7(4.7)$ & 0 \\
\hline \multicolumn{4}{|l|}{$\begin{array}{l}\text { Intent to return } \\
\text { after training if } \\
\text { they migrate }\end{array}$} \\
\hline Yes & $114(76.5)$ & $88(59.1)$ & $26(17.4)$ \\
\hline Maybe & $29(19.4)$ & $22(14.8)$ & $7(4.6)$ \\
\hline No & $6(4.0)$ & $5(3.3)$ & $1(0.7)$ \\
\hline $\begin{array}{l}\text { Change of mind } \\
\text { on the preferred } \\
\text { residency program }\end{array}$ & $87(58.3)$ & $69(46.3)$ & $18(12.1)$ \\
\hline $\begin{array}{l}\text { Advised to go into } \\
\text { a particular } \\
\text { specialty }\end{array}$ & $133(89.3)$ & $101(67.8)$ & $32(21.5)$ \\
\hline $\begin{array}{l}\text { Followed the } \\
\text { advice }\end{array}$ & $64(43.0)$ & $47(31.5)$ & $17(11.4)$ \\
\hline $\begin{array}{l}\text { Advised not to go } \\
\text { into a particular } \\
\text { specialty }\end{array}$ & $66(44.3)$ & $51(34.2)$ & $15(10.1)$ \\
\hline $\begin{array}{l}\text { Followed the } \\
\text { advice }\end{array}$ & $24(16.1)$ & $22(14.8)$ & $3(2.0)$ \\
\hline
\end{tabular}

Figure 1. Preferred Destinations of Cameroonian and Congolese Senior Medical Students for Postgraduate Medical Training.
The most popular first choice specialties in our study were cardiology $14(9.4 \%)$, pediatrics $14(9.4 \%)$, and obstetrics and gynecology 13 (8.7\%). $24.7 \%$ of women chose a surgical specialty, while $14.3 \%$ chose pediatrics as their first choice. On the other hand, $44.4 \%$ of men chose a surgical specialty, while $4.2 \%$ chose pediatrics as their first choice (Table 2).

The majority of study participants identified personal skills for the job $(85.9 \%)$, patient contact $(79.2 \%)$, and anticipated pay after residency (79.2\%) as being essential to choosing a residency program (Figure 2). Eighty-eight students $(55.7 \%$ ) estimated the specialist average monthly salary to be above USD $\$ 1,070$, the median of the specialist monthly wage estimation was USD $\$ 982-1,070$, and the mode was .USD $\$ 1,607$ $(25.5 \%) .83(55.7 \%)$ felt there was no factor other than the pre-identified 11 that influenced their residency choice. Other factors reported included a passion for the specialty $(8.1 \%)$, lesser popularity of the specialty $(6.0 \%)$, and family $(3.4 \%)$. The main reason for not liking a specialty was a lack of interest $(58.4 \%)$.

We found a statistically significant small to moderate association between male gender and having been discouraged from doing a particular specialty (Phi $-0.213, p=0.009$ ). Enrollment at a public or private school $(p=0.859)$, being discouraged $(p=0.619)$, and being encouraged $(p=1.000)$ by someone to do a particular specialty were not found to be associated with specialty choice. No association was found between the intent to specialize on the one hand and deciding on whether to practice in a rural area $(p=1.000)$, being encouraged to do a specialty $(p=0.113)$, and being discouraged from doing a specialty $(p=0.013)$. The choice of specialty was significantly associated with perceived specialty prestige $(p=0.04)$ and previous experience $(p=0.05)$. Multinomial analysis of the level of agreement on the importance of the determinants by preferred specialty revealed that indecision on the importance of prestige $(p=0.004)$ and strong disagreement/ disagreement of the importance of previous experience $(p=0.02)$ to specialty choice were both statistically significant among students who chose specialties that were neither medical nor surgical (Table 3).

Table 2. Cameroonian and Congolese Medical Students' First Specialty Choice by Frequency and Percentage.

\begin{tabular}{|c|c|c|c|}
\hline Specialty & $\begin{array}{c}\text { All }[n(\%)] \\
n=149\end{array}$ & $\begin{array}{c}\text { Female } \\
{[\mathrm{n}(\%)]} \\
n=77\end{array}$ & $\begin{array}{c}\text { Male } \\
{[n(\%)]} \\
n=72\end{array}$ \\
\hline Medical specialties & $37(24.8)$ & $21(14.1)$ & $16(10.7)$ \\
\hline Cardiology & $14(9.4)$ & $7(4.7)$ & $7(4.7)$ \\
\hline Endocrinology and diabetology & $5(3.4)$ & $4(2.7)$ & $1(0.7)$ \\
\hline Gastroenterology & $4(2.7)$ & $2(1.3)$ & $2(1.3)$ \\
\hline General internal medicine & $3(2.0)$ & $2(1.3)$ & $1(0.7)$ \\
\hline Infectious diseases & $2(1.3)$ & 0 & $2(1.3)$ \\
\hline Nephrology & $6(4.0)$ & $3(2.0)$ & $3(2.0)$ \\
\hline Oncology & $2(1.3)$ & $2(1.3)$ & 0 \\
\hline Pneumonology & $1(0.7)$ & $1(0.7)$ & 0 \\
\hline Surgical specialties & $51(34.2)$ & $19(13)$ & $32(21.5)$ \\
\hline Cardiothoracic surgery & $6(4.0)$ & $2(1.3)$ & $4(2.7)$ \\
\hline General surgery & $10(6.7)$ & $6(4.0)$ & $4(2.7)$ \\
\hline Maxillofacial and oral surgery & $3(2.0)$ & $3(2.0)$ & 0 \\
\hline Neurosurgery & $10(6.7)$ & $2(1.3)$ & $8(5.4)$ \\
\hline Otolaryngology & $3(2.0)$ & $1(0.7)$ & $2(1.3)$ \\
\hline Pediatric surgery & $6(4.0)$ & $3(2.0)$ & $3(2.0)$ \\
\hline Plastic surgery & $4(2.7)$ & $1(0.7)$ & $3(2.0)$ \\
\hline Trauma and orthopedic surgery & $7(4.7)$ & $1(0.7)$ & $6(4.0)$ \\
\hline Vascular surgery & $2(1.3)$ & 0 & $2(1.3)$ \\
\hline Other specialties & $61(41)$ & $37(25)$ & $24(16.1)$ \\
\hline Anesthesia & $3(2.0)$ & $1(0.7)$ & $2(1.3)$ \\
\hline $\begin{array}{l}\text { Clinical and therapeutic } \\
\text { pharmacology }\end{array}$ & $1(0.7)$ & 0 & $1(0.7)$ \\
\hline $\begin{array}{l}\text { Community and sexual } \\
\text { reproductive health }\end{array}$ & $1(0.7)$ & $1(0.7)$ & 0 \\
\hline Neurology & $3(2.0)$ & $1(0.7)$ & $2(1.3)$ \\
\hline Obstetrics and gynecology & $13(9)$ & $7(5)$ & $6(4.0)$ \\
\hline Occupational medicine & $1(0.7)$ & 0 & $1(0.7)$ \\
\hline Ophthalmology & $5(3.4)$ & $4(2.7)$ & $1(0.7)$ \\
\hline Pediatrics & $14(9.4)$ & $11(7.4)$ & $3(2.0)$ \\
\hline Psychiatry & $3(2.0)$ & $1(0.7)$ & $2(1.3)$ \\
\hline Public health & $8(5.4)$ & $6(4.0)$ & $2(1.3)$ \\
\hline Radiology & $7(4.7)$ & $5(3.4)$ & $2(1.3)$ \\
\hline Resuscitation medicine & $1(0.7)$ & 0 & $1(0.7)$ \\
\hline Sports medicine & $1(0.7)$ & 0 & $1(0.7)$ \\
\hline
\end{tabular}


Figure 2. Factors Influencing the Choice of a Specialty and the Level of Agreement of Sixth- and Seventh Year Medical Students.

Social prestige

Advice by a family member

Advice by a mentor

Previous exposure to specialty

Skills

Patient contact

Remuneration after residency

Remuneration during residency

Work hours

Cost of training

Length of training

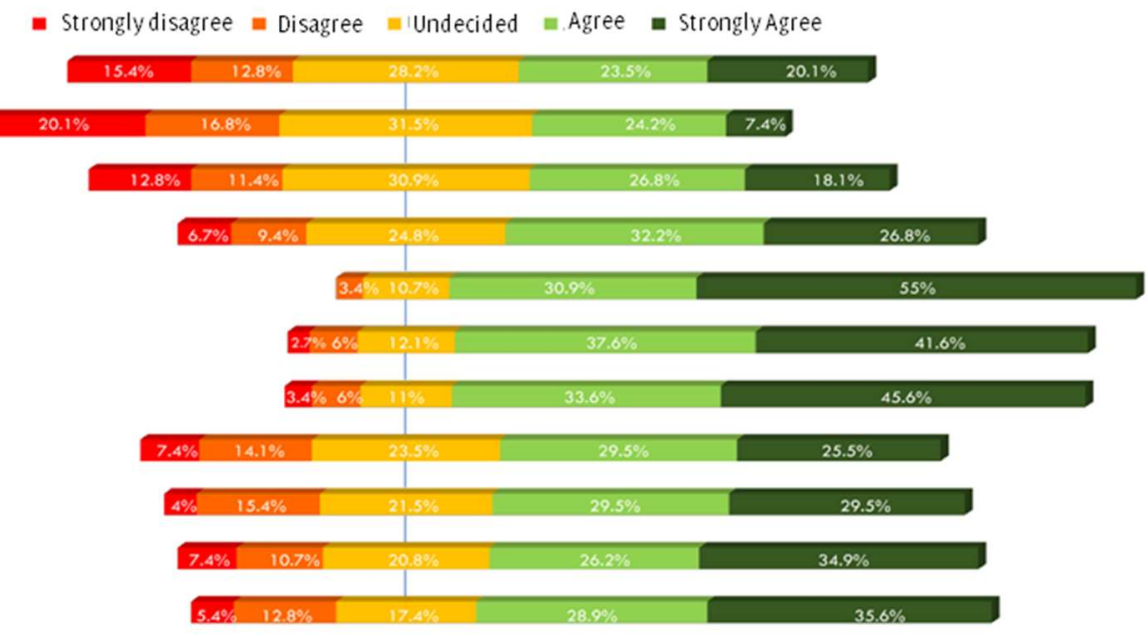

Table 3. Multinomial Regression Analysis of Specialty Determinants and Medical Students' Specialty Choice.

\begin{tabular}{|c|c|c|c|c|c|c|c|c|c|}
\hline \multirow{2}{*}{ Determinant a } & \multicolumn{3}{|c|}{ Internal medicine ${ }^{b}$} & \multicolumn{3}{|c|}{ Other specialties ${ }^{b}$} & \multirow{2}{*}{ Intercept } & \multirow{2}{*}{$x^{2}$} & \multirow{2}{*}{$p$-value } \\
\hline & S.E. & Wald & $p$-value & S.E. & Wald & $\mathrm{p}$-value & & & \\
\hline Advice by a family member & & & & & & & 25.14 & 0.62 & 0.96 \\
\hline Strongly disagree/disagree & 0.52 & 0.07 & 0.80 & 0.46 & 0.27 & 0.61 & & & \\
\hline Undecided & 0.53 & 0.03 & 0.87 & 0.49 & 0.21 & 0.67 & & & \\
\hline Advice by a mentor & & & & & & & 29.55 & 5.41 & 0.25 \\
\hline Strongly disagree/disagree & 0.54 & 2.96 & 0.09 & 0.48 & 1.00 & 0.32 & & & \\
\hline Undecided & 0.51 & 0.18 & 0.68 & 0.46 & 0.73 & 0.39 & & & \\
\hline Cost of training & & & & & & & 25.14 & 1.55 & 0.82 \\
\hline Strongly disagree/disagree & 0.56 & 0.24 & 0.62 & 0.52 & 0.04 & 0.84 & & & \\
\hline Undecided & 0.56 & 0.84 & 0.63 & 0.51 & 1.22 & 0.27 & & & \\
\hline Length of training & & & & & & & 25.11 & 3.83 & 0.42 \\
\hline Strongly disagree/disagree & 0.56 & 1.56 & 0.21 & 0.52 & 4.15 & $0.04^{*}$ & & & \\
\hline Undecided & 0.56 & 0.23 & 0.63 & 0.54 & 0.22 & 0.64 & & & \\
\hline Patient contact & & & & & & & 25.11 & 3.83 & 0.42 \\
\hline Strongly disagree/disagree & 0.73 & 1.09 & 0.30 & 0.72 & 2.25 & 0.13 & & & \\
\hline Undecided & 0.73 & 1.09 & 0.30 & 0.56 & 0.04 & 0.85 & & & \\
\hline Prestige & & & & & & & 34.30 & 10.18 & $0.04^{*}$ \\
\hline Strongly disagree/disagree & 0.50 & 2.45 & 0.12 & 0.48 & 2.40 & 0.12 & & & \\
\hline Undecided & 0.55 & 1.76 & 0.19 & 0.49 & 8.09 & $0.004^{\star *}$ & & & \\
\hline Previous experience & & & & & & & 32.92 & 9.61 & $0.05^{*}$ \\
\hline Strongly disagree/disagree & 0.54 & 0.09 & 0.77 & 0.64 & 5.88 & $0.02^{*}$ & & & \\
\hline Undecided & 0.52 & 1.56 & 0.21 & 0.45 & 2.69 & 0.10 & & & \\
\hline Remuneration after residency & & & & & & & 23.77 & 2.20 & 0.70 \\
\hline Strongly disagree/disagree & 0.77 & 0.05 & 0.82 & 0.64 & 0.02 & 0.89 & & & \\
\hline Undecided & 0.67 & 1.78 & 0.18 & 0.68 & 0.21 & 0.64 & & & \\
\hline Remuneration during residency & & & & & & & 26.02 & 2.15 & 0.71 \\
\hline Strongly disagree/disagree & 0.56 & 0.47 & 0.49 & 0.51 & 1.70 & 0.19 & & & \\
\hline Undecided & 0.53 & 0.17 & 0.68 & 0.47 & 0.05 & 0.82 & & & \\
\hline Skill & & & & & & & 24.13 & 6.35 & 0.18 \\
\hline Strongly disagree/disagree & 0 & & & 0.94 & 0.06 & 0.80 & & & \\
\hline Undecided & 0.82 & 2.54 & 0.11 & 0.58 & 0.65 & 0.42 & & & \\
\hline Work hours & & & & & & & 33.40 & 9.90 & 0.42 \\
\hline Strongly disagree/disagree & 0.54 & 0.03 & 0.87 & 0.52 & 1.60 & 0.20 & & & \\
\hline Undecided & 0.52 & 1.64 & 0.20 & 0.52 & 7.84 & $0.005^{* *}$ & & & \\
\hline
\end{tabular}

\section{Discussion}

Cameroonian and Congolese students, like their Kenyan colleagues, wish to get into residency. ${ }^{19}$ PGME fosters learning and mastery of a medical specialty in a formal setting and affords physicians career opportunities, higher social standing, and better remuneration. Cameroonian general practitioners in the public sector earn between USD \$262 - \$292 on average per month as opposed to the highest
Cameroonian specialist earners, surgeons, who earn up to USD $\$ 1,491$ per month on average. ${ }^{20}$ Medical students estimated specialists earned an average monthly salary of USD $\$ 1,607$, well above the USD $\$ 300-$ $\$ 600$ monthly income of the African middle-class, and they felt remuneration after residency was critical when choosing their future specialty. ${ }^{21}$ 
Cameroonian and Congolese students rotate through surgery, obstetrics and gynecology, pediatrics, and internal medicine. During this period, they develop skills, and they get to build bonds with patients in these departments. They equally experience the challenges of medical practice and PGME training in-country. PGME in developing countries is faced with a lack of financial resources, a dearth of qualified medical educators, and these impact the quality of PGME training. ${ }^{22,23}$ Few local residency programs can compete with the resources and prestige of foreign programs. While residency programs of developed nations have successfully integrated innovative solutions to their PGME, ${ }^{24-26}$ residency programs in low-resource settings, often lack residency spots and the infrastructure necessary for quality PGME training. Local programs must develop novel, sustainable, and low-cost solutions in order to improve the quality of their PGME and to garner the attention of their medical students. Some programs, like the College of Surgeons of East, Central and Southern Africa, and the West African College of Surgeons, have successfully developed training models that make use of foreign and local resources. This combination has led to an increase in the number of trained specialists and high retention of graduates on the African continent.

Admission to foreign residency programs is extremely competitive and costly. ${ }^{27}$ African countries lose financial and human resources to Western countries as those willing to study in world-renowned institutions migrate. Having quality local PGME programs can reduce brain drain from medical workforce migration and reduce capital flight. Similarly to our survey participants, $88.2 \%$ of medical students in Malawis, and $69 \%$ of medical students in Botswana ${ }^{6}$ intend to train abroad.

In contrast, South African medical students prefer to study in their home country. ${ }^{28}$ South Africa, unlike most sub-Saharan African countries, is advanced economically and scientifically. Its medical education is reputed for its quality medical education and research. ${ }^{29,30}$ This might explain why less South Africans are willing to go abroad for their specialization while most Cameroonians and Congolese wish to go to more developed countries like South Africa for their PGME. This difference is corroborated by the fact that most survey respondents chose to train in their favorite specialty at home instead of training in their least favorite specialty abroad.

Although most medical students intend to migrate, they are equally willing to return home once they complete their training. Return to practice in a low-resource setting can be a daunting task for a physician who has become accustomed to working in the Western world. Often newly graduated specialists return home to hospitals that lack equipment and often have to build a service from the ground up. If a residency program is not available in-country, training in an African country offers an environment similar to the home country. It is encouraging that a considerable number of students chose African countries as their destination for PGME training.

Specialties that offer medical students with greater exposure to patients tend to elicit a greater sense of confidence. The confidence that medical students have in their clinical ability increases with supervision, and transition from the lab to the bedside. ${ }^{31}$ Both previous exposure to future specialty and perceived skill were essential factors in the choice of future medical specialty to our participants. Similarly, Brazilian medical students emphasize previous experience, perceived skill, and patient contact.32 Remuneration is equally vital in the choice of a specialty. Although American military medical students choose their specialty based on interest when compensated reasonably, they are more likely to choose less-desirable specialties. ${ }^{33}$ We posit that the choice by our respondents of pay after residency can be attributed to the fact that medical training is costly, lengthy and demanding. Medical school tuition can cost as much as USD \$2,279 in some Cameroonian and Congolese private schools, and training lasts at least seven years in both countries. In the DRC, it is not uncommon for medical students to graduate with a delay of up to 18 months. This delay, année élastique (elastic year), often occurs during the seventh academic year. This is a stressful period for students given that they do not have a medical license, they cannot take up remunerated jobs and therefore depend on their parents for financial assistance. This in part explains the strong desire to train abroad where there are less uncertainties.

Sub-Saharan Africa has the lowest regional medical workforce despite having the highest burden of disease in the world. ${ }^{34}$ We must pay attention to those specialties that have a high burden of disease to workforce ratio through strategies aimed at those who are least interested or least represented. Local governments should partner with their medical diaspora and foreign partners to develop quality residency programs and opportunities for medical students. The medical diaspora and foreign medical bodies have the skills, resources, and experience to help bring these plans to fruition 35 , but it is up to local governments to develop policies that incentivize their participation.

Limitations to the study include the small sample size and low representation of Congolese medical students. Their low representation might be due to the expensive cost of broadband, USD $\$ 1$ buys between 130-165 Mb of broadband in the DRC, and most students cannot afford the internet daily. Secondly, by choosing a cross-sectional study design, we could only establish correlation and not causation. The fact that $58.4 \%$ of respondents reported having changed their mind before on their specialty choice suggests that some might change their minds in the future. Ideally, we should have followed our participants from medical school to their admission into residency to establish if they had changed their minds. However, this was not possible due to a lack of resources. Next, surveys are prone to a multitude of biases, which can complicate their interpretation. We minimized social response bias by guaranteeing anonymity to our respondents and addressed nonresponse bias and self-selection bias by sharing our survey by text and WhatsApp while sending reminders every ten days. Despite these limitations, we believe our findings give an insight into some of the motivations of Cameroonian and Congolese medical students who wish to get into a residency program. Future studies should focus on whether these future African medical doctors get into the residency program of their choice, whether they succeed in migrating to the country of their choice and whether they return once they have been trained abroad. Such studies can inform the decision-makers as they design PGME programs.

Medical students from Cameroon and the Democratic Republic of Congo are eager to get into a specialty. They wish to have the best PGME and are willing to travel for this purpose. Their preferred destinations for training are France, Canada, and the United States. Cardiology, pediatrics, and obstetrics and gynecology are the most popular specialties, and their choice is influenced by skills, patient contact, and remuneration after residency. Local program directors must evaluate the quality of programs currently available and modify them to meet the expectations of medical students. 


\section{References}

1. Wagstaff A, Flores G, Hsu J, Smitz MF, Chepynoga K, Buisman LR, et al. Progress on catastrophic health spending in 133 countries: a retrospective observational study. Lancet Glob Health. 2018 Feb;6(2):e169-e179.

2. World Bank. Current health expenditure (\% of GDP) | Data. 2019 ed: The World Bank Group; 2019p.

3. Awosusi AE. Aftermath of Boko Haram violence in the Lake Chad Basin: a neglected global health threat. BMJ Glob Health. 2017 Jan 5;2(1):e000193.

4. Ilunga Kalenga 0 , Moeti M, Sparrow A, Nguyen V-K, Lucey D, Chebreyesus TA. The Ongoing Ebola Epidemic in the Democratic Republic of Congo, 2018-2019. N Engl J Med. 2019 Jul 25;381(4):373-383.

5. Yeganeh-Arani E, Chandratilake M, Muula AS. Factors affecting career preferences of medical students at the College of Medicine, Malawi. S Afr Med J. $2012 \operatorname{Mar} 7 ; 102(4): 249-51$.

6. Rukewe A, Abebe WA, Fatiregun AA, Kgantshang M. Specialty preferences among medical students in Botswana. BMC Res Notes. 2017 Jun 8;10(1):195.

7. Vollmer WM, Swain MC. Role of the specialist in the treatment of asthma. Curr Opin Allergy Clin Immunol. 2002 Jun;2(3):189-94.

8. Jain SR, Hosseini-Moghaddam SM, Dwek P, Gupta K, Elsayed S, Thompson GW, et al. Infectious diseases specialist management improves outcomes for outpatients diagnosed with cellulitis in the emergency department: a double cohort study. Diagn Microbiol Infect Dis. 2017 Apr;87(4):371-375.

9. Meghen K, Sweeney C, Linehan C, O'Flynn S, Boylan C. Women in hospital medicine: facts, figures and personal experiences. Ir Med J. 2013 Feb;106(2):3942.

10. Venkatesh B, Mehta S, Angus DC, Finfer S, Machado FR, Marshall J, et al. Women in Intensive Care study: a preliminary assessment of international data on female representation in the ICU physician workforce, leadership and academic positions. Crit Care. 2018 Sep 10;22(1):211.

11. Price M, Weiner R. Where have all the doctors gone? Career choices of Wits medical graduates. S Afr Med J. 2005 Jun;95(6):414-9.

12. McMurray JE, Cohen M, Angus G, Harding J, Gavel P, Horvath J, et al. Women in medicine: a four-nation comparison. J Am Med Womens Assoc (1972). 2002 Fall; $57(4): 185-90$.

13. de Vries E, Irlam J, Couper I, Kornik S, Health Equity through E, Research. Career plans of final-year medical students in South Africa. S Afr Med J. 2010 Mar 30;100(4):227-8.

14. Alawad AA, Khan WS, Abdelrazig YM, Elzain YI, Khalil HO, Ahmed OB, et al. Factors considered by undergraduate medical students when selecting specialty of their future careers. Pan Afr Med J. 2015 Feb 4;20:102.

15. World Bank. Cameroon. 2019 ed: The World Bank Group; 2019p..

16. World Bank. Congo, Dem. Rep. 2019 ed: The World Bank Group; 2019.
17. Chen C, Buch E, Wassermann T, Frehywot S, Mullan F, Omaswa F, et al. A survey of Sub-Saharan African medical schools. Hum Resour Health. 2012 Feb 24;10:4.

18. Ntembwa HK, Van Lerbeghe W. Improving Health Systems Efficiency - Democratic Republic of the Congo. Democratic Republic of Congo: World Health Organisation; 20152015.

19. Maseghe Mwachaka P, Thuo Mbugua E. Specialty preferences among medical students in a Kenyan university. Pan Afr Med J. 2010 Jun 8;5:18.

20. Surgeon Salary in Cameroon. Job and Salary Abroad. 2019 [cited 2019 11/23/2019]; Available from: https://www.jobandsalaryabroad.com/en/cameroon/english-surgeoncameroon.html

21. Few and far between. The Economist. 2015 2015-10-22T14:50:18Z, 2015-1022T14:50:18Z.

22. Kucheryavenko 0. Shortcomings of Medical Education in Developing Countries. Cochrane Consumer Network.

23. Celletti F, Buch E, Samb B. Medical education in developing countries: Oxford University Press $\mathrm{p}$.

24. Takayesu JK, Nadel ES, Bhatia K, Walls RM. Incorporating simulation into a residency curriculum. CJEM. 2010 Jul;12(4):349-53.

25. Wittich CM, Agrawal A, Cook DA, Halvorsen AJ, Mandrekar JN, Chaudhry S, et al. E-learning in graduate medical education: survey of residency program directors. BMC Med Educ. 2017 Jul 11;17(1):114.

26. Fogel HA, Liskutin TE, Wu K, Nystrom L, Martin B, Schiff A. The Economic Burden of Residency Interviews on Applicants. Iowa Orthop J. 2018;38:9-15.

27. Van Wyk J, Naidoo S, Esterhuizen T. Will graduating medical students prefer to practise in rural communities? S Afr Fam Pract. 2010;52(2):149-153.

28. Cooper DK. Christiaan Barnard and his contributions to heart transplantation. J Heart Lung Transplant. 2001 Jun;20(6):599-610.

29. Mansoorian MR, Jalili M, Khosravan S, Shariati M. Exploring undergraduate medical students' perception of learning procedural skills and its outcomes in clinical settings. J Adv Med Educ Prof. 2019 Oct;7(4):175-182.

30. Correia Lima de Souza L, Mendonca VR, Garcia GB, Brandao EC, Barral-Netto M Medical Specialty Choice and Related Factors of Brazilian Medical Students and Recent Doctors. PLoS One. 2015 Jul 24;10(7):e0133585.

31. DeZee KJ, Maurer D, Colt R, Shimeall W, Mallory R, Powers J, et al. Effect of financial remuneration on specialty choice of fourth-year U.S. medical students. Acad Med. 2011 Feb;86(2):187-93.

32. World Health Organization. Migration of health workers: WHO code of practice and the global economic crisis. Geneva: World Health Organization; 2014p.

33. Wojczewski S, Poppe A, Hoffmann K, Peersman W, Nkomazana 0, Pentz S, et al. Diaspora engagement of African migrant health workers - examples from five destination countries. Glob Health Action. 2015 Dec 9;8:29210.

\section{Acknowledgments}

Leah Moody and Dominique Vervoort served as scientific advisors. Samuel Mbom, Olga Djoutsop, and Ornella Pokam collected data and helped with the dissemination of the survey.

Conflict of Interest Statement at Funding

The Authors have no funding, financial relationships or conflicts of interest to disclose.

\section{Author Contributions}

Conceptualization: USK, MT, and FTE. Methodology: USK, MT, and FTE. Validation: MT and FTE. Formal Analysis: USK, MT, and FTE. Data Curation: USK. Investigation: USK, MT, and FTE. Writing - Original Draft: USK, MT, and FTE. Writing - Review $九$ Editing: USK, MT, and FTE. Visualization: USK. Supervision: MT and FTE. Project Administration: USK, MT, and FTE.

Cite as:

Kanmounye US, Temgoua M, Endomba FT. Determinants of Residency Program Choice in Two Central African Countries: An Internet Survey of Senior Medical Students. Int J Med Students. 2020 Jan-Apr;8(1):20-25. 